\title{
Behavioural thermoregulation linked to foraging in blue sharks
}

\author{
Yuuki Y. Watanabe ${ }^{1,2}\left(\right.$ Itsumi Nakamura $^{3} \cdot$ Wei-Chuan Chiang ${ }^{4}$
}

Received: 28 June 2021 / Accepted: 17 September 2021 / Published online: 22 October 2021

(c) The Author(s), under exclusive licence to Springer-Verlag GmbH Germany, part of Springer Nature 2021

\begin{abstract}
Large pelagic fishes often dive and surface repeatedly as if they were airbreathers, raising a question about the functions of these movements. Some species (e.g., bigeye tuna, ocean sunfish) apparently alternate foraging in deep cold waters and rewarming in shallow warm waters. However, it is unclear how prevalent this pattern is among species. Blue sharks are the widest-ranging pelagic shark with expanded vertical niches, providing a model for studying foraging-thermoregulation associations. We used electronic tags, including video cameras, to record the diving behaviour, muscle temperature, and foraging events of two blue sharks. During repeated deep dives (max. $422 \mathrm{~m}$ ), muscle temperature changed more slowly than ambient water temperature. Sharks shifted between descents and ascents before muscle temperature reached ambient temperature, leading to a narrower range $\left(8{ }^{\circ} \mathrm{C}\right)$ of muscle temperature than ambient temperature $\left(20^{\circ} \mathrm{C}\right) \cdot 2 \cdot 5$-h video footage showed a shark catching a squid, during which a burst swimming event was recorded. Similar swimming events, detected from the entire tag data $(20-22 \mathrm{~h})$, occurred over a wide depth range $(5-293 \mathrm{~m})$. We conclude that, instead of alternating foraging and rewarming, blue sharks at our study site forage and thermoregulate continuously in the water column. Furthermore, our comparative analyses showed that the heat exchange rates of blue sharks during the warming and cooling process were not exceptional among fishes for their body size. Thus, behavioural thermoregulation linked to foraging, rather than enhanced abilities to control heat exchange rates, is likely key to the expanded thermal niches of this ectothermic species.
\end{abstract}

Keywords Biologging $\cdot$ Body temperature $\cdot$ Foraging behaviour $\cdot$ Heat exchange model

\section{Introduction}

Marine environments are characterised by vertical gradients of physical (e.g., temperature, light level, oxygen concentration) and biological properties (e.g., primary production). These gradients, coupled with eco-physiological characteristics of each

Responsible Editor: J. Carlson.

Yuuki Y. Watanabe

watanabe.yuuki@nipr.ac.jp

1 National Institute of Polar Research, Tachikawa, Tokyo 190-8518, Japan

2 Department of Polar Science, The Graduate University for Advanced Studies, SOKENDAI, Tachikawa, Tokyo 190-8518, Japan

3 Organization for Marine Science and Technology, Nagasaki University, Nagasaki City, Nagasaki 851-2213, Japan

4 Eastern Marine Biology Research Center, Fisheries Research Institute, Chenggong, Taitung County 961, Taiwan species and intra- and interspecific interactions such as competition and predation, determine the vertical distributions of marine animals (Longhurst 1967; Giske et al. 1990). Yet, many marine animals do not stay at a particular depth but exhibit vertical return movements or oscillations with various cycles and amplitudes (Hays 2003; Andrzejaczek et al. 2019). Vertical movements at a daily cycle, exhibited by a range of zooplankton and nektons, are primarily caused by diel changes in light intensity and associated shifts in predation risk and prey availability (Hays 2003). Instead of (or in addition to) a daily cycle, large pelagic fishes, including teleosts and elasmobranchs, perform dives many times a day (Andrzejaczek et al. 2019). Fish movements between the surface and great depth are often so consistent that their depth profiles are similar to those of airbreathers (e.g., seals) (Watanabe et al. 2019). This general phenomenon among large pelagic fishes has interested researchers for decades (Carey and Scharold 1990). Proposed functions, which are not mutually exclusive and may depend on species and the environment, include foraging, locomotion cost saving, thermoregulation, and navigation (Weihs 1973; Carey and Scharold 1990; Klimley 1993; Andrzejaczek et al. 2019). 
Increasingly sophisticated electronic tags have allowed recording of the behaviour, internal states, and environments of free-living pelagic fishes, providing insights into how and why they dive. Empirical records of fish body temperature indicate that thermoregulation associated with foraging is a main function of diving behaviour, at least in bigeye tunas Thunnus obesus (Holland et al. 1992) and ocean sunfish Mola mola (Nakamura et al. 2015). During the descending phase of dives, the ambient water temperature decreases rapidly, whereas the body temperature of these fishes decreases slowly due to large thermal inertia (i.e., low surface-areato-volume ratio). They can thus make short excursions to deep cold waters for foraging without excessively lowering their body temperature, given that they rewarm at shallow depths after the excursions. Moreover, whole-body heat transfer coefficients (i.e., the rate of change in body temperature for a unit difference between body temperature and ambient temperature) of large pelagic fishes can be higher during the ascending (i.e., warming) phase of dives than the descending (i.e., cooling) phase (Holland et al. 1992; Nakamura et al. 2015, 2020). This observation indicates that they can enhance the body warming process physiologically, leading to shorter post-dive durations and higher foraging efficiencies in a dive cycle (Nakamura et al. 2015). However, it is currently unknown how prevalent this pattern is among large pelagic fishes.

Blue sharks Prionace glauca are the most abundant pelagic shark distributed globally in tropical and temperate waters. They are an ectothermic species without the parallel arrangement of arteries and veins that function as counter-current heat exchangers in muscles (Carey and Gibson 1987). In general, ectothermic fishes are thought to have narrower thermal niches than regionally endothermic fishes with well-developed heat exchangers (e.g., tunas, lamnid sharks) (Block et al. 1993; Weng et al. 2005), although a recent study challenged this view (Harding et al. 2021). Blue sharks represent an interesting example as they dive to great depths [occasionally $>1000 \mathrm{~m}$, with the maximum record of $1706 \mathrm{~m}$ (Queiroz et al. 2017)] and experience extensive water temperature ranges (up to $20^{\circ} \mathrm{C}$ ) (Stevens et al. 2010; Campana et al. 2011; Queiroz et al. 2012) despite their ectothermic physiology. They feed on a range of prey (e.g., teleosts, cephalopods, pelagic crustaceans) in the water column (Markaida and Sosa-Nishizaki 2010), unlike bigeye tunas and ocean sunfish that have more specialised diets and forage primarily in deep waters. We hypothesised, therefore, that blue sharks would exhibit different thermoregulatory and foraging behaviour from bigeye tunas and ocean sunfish, which apparently alternate foraging in deep waters and rewarming in shallow waters. A previous study that recorded blue shark body temperature and diving behaviour showed that they change vertical swimming directions (descending or ascending) before their body temperature reaches the ambient water temperature (Carey and Scharold 1990). Consequently, shark body temperature falls within a narrow range, supporting the thermoregulatory function of repeated deep dives (Carey and Scharold 1990). However, foraging events were neither recorded in that study nor any other blue shark tagging studies; therefore, possible associations between thermoregulation and foraging remain unknown.

In this study, we attached a biologging package, including multi-sensor data loggers and a video camera, to two free-living blue sharks and recorded their diving behaviour, muscle temperature, and foraging events. We aimed to understand the behavioural thermoregulation strategy and its association with foraging behaviour in blue sharks. Furthermore, to assess their abilities to control heat exchange rates, we estimated their whole-body heat transfer coefficients during the warming and cooling process and compared the values to other species reported in the literature.

\section{Materials and methods}

\section{Fieldwork and instrumentation}

Fieldwork was conducted off Taitung $\left(\mathrm{N} 23.13^{\circ}, \mathrm{E} 121.53^{\circ}\right)$, south-eastern Taiwan, in the Pacific Ocean in June 2019. Two blue sharks captured by longline were brought onboard, measured, instrumented, and then released into the water. Body mass was estimated from fork length (Kohler et al. 1995). For each animal, a biologging package composed of an accelerometer (W1000-PD3GT, Little Leonardo), video camera (DVLW400M130-4R, Little Leonardo), depth-temperature recorder (LAT1810, Lotek), float, time-scheduled release mechanism (Little Leonardo), satellite transmitter (Wildlife Computers), and radio transmitter (Advanced Telemetry Systems) was attached. The W1000-PD3GT accelerometer recorded depth, ambient water temperature, and swim speed at $1 \mathrm{~s}$ intervals, and tri-axial acceleration at $1 / 16 \mathrm{~s}$ intervals for the 1-day deployment period. The DVLW400M130-4R camera recorded images of $640 \times 480$ pixels at 30 frames per second with near red flash. The camera was facing forward on the shark's back, and programmed to start filming 7-8 $\mathrm{h}$ after the release (at 15:30 local time) and record continuously until the battery ran out in $2.5 \mathrm{~h}$. The LAT1810 recorder had a $15-\mathrm{cm}$ stalk temperature sensor and recorded depth, ambient water temperature, and muscle temperature (see below) at $1 \mathrm{~s}$ intervals for the deployment period. A package weighed $350 \mathrm{~g}$, representing $1.2 \%$ of the mean estimated body mass of the sharks $(29.5 \mathrm{~kg})$.

A small hole was penetrated horizontally through the shark's skin on the back anterior to the first dorsal fin. A thin plastic cable connected to the time-scheduled release mechanism was passed through the hole and the biologging package was secured (Watanabe et al. 2008). To record muscle 
temperature, another small hole was pierced vertically on the back and the stalk temperature sensor of the Lotek recorder was inserted into the muscle to approximately $15 \mathrm{~cm}$ depth (Nakamura et al. 2015). The plastic cable was cut by an electric charge $20-22 \mathrm{~h}$ after the release and the whole package, including the stalk temperature sensor, detached from the animals and floated to the surface. It was located via radio telemetry and recovered by a boat (Watanabe et al. 2004).

In January 2020, a dead male blue shark (fork length, $211 \mathrm{~cm}$ ) with internal organs removed was obtained at the Shinkang fish market and transported to the Eastern Marine Biology Research Center of Fisheries Research Institute. A biologging package composed of a Little Leonardo accelerometer and Lotek recorder was attached in the same manner as the live sharks. The dead shark was placed in two pools with different water temperature $\left(23\right.$ and $\left.7{ }^{\circ} \mathrm{C}\right)$ for $2 \mathrm{~h}$ each.

Since then, travel restrictions due to the COVID-19 pandemic have precluded us from collecting more data from wild individuals.

\section{Tag data analyses}

Tag data were analysed using the software Igor Pro (WaveMetrics). To characterise the repeated vertical movements of the sharks, a dive was defined as an event in which sharks remained below $50 \mathrm{~m}$ depth. The threshold of $50 \mathrm{~m}$ was chosen because blue sharks and other pelagic sharks do not necessarily ascend to the top surface following excursions to deep waters, and because they sometimes exhibit constant ranging behaviour in the top $50 \mathrm{~m}$ layer (Queiroz et al. 2017; Andrzejaczek et al. 2018). Relative swim speed, measured by the propeller sensor of the Little Leonardo accelerometer, was converted to actual swim speed $\left(\mathrm{m} \mathrm{s}^{-1}\right)$ based on a flow-tank calibration experiment (Watanabe et al. 2019). Accelerometers were not perfectly aligned on the animals' back, potentially leading to decreased propeller rotation rates and underestimates of shark swim speed. To account for this effect, the pitch angle of the accelerometer was calculated from low-pass filtered longitudinal acceleration (Tanaka et al. 2001). Then, the difference between the accelerometer pitch angle and shark pitch angle was estimated, assuming that shark pitch angle is zero when the rate of depth change is zero (Kawatsu et al. 2010). The raw swim speed estimates were divided by the cosine of the angle difference to obtain the corrected swim speed estimates (Watanabe et al. 2019). Tailbeat activities were examined from high-pass filtered lateral accelerations. Gliding behaviour, in which sharks stopped tailbeats, was detected visually as the periods showing no cyclic changes in high-pass filtered lateral accelerations (Watanabe et al. 2019). Animal-borne video footage, which partially covered the recording periods of accelerometers, was checked for the presence of prey capture events. The event seen in the footage was linked to the specific behavioural signal (i.e., increased swim speed) recorded by accelerometers, and the signal was detected from the entire accelerometer data to characterise shark foraging behaviour (Watanabe and Takahashi 2013). Besides swim speed, tailbeat activities based on lateral acceleration could also function as a behavioural signal of prey capture events. However, because the baseline tailbeat activities differed between the descending and ascending phase of dives, increased swim speed was deemed a simpler signal in this study.

A heat exchange model was used to estimate the wholebody heat transfer coefficients of blue sharks during the warming and cooling process (Weller et al. 1984; Holland et al. 1992; Malte et al. 2007; Nakamura et al. 2015). Heat exchange of an animal at a time $t$ can be expressed as:

$\mathrm{d} T_{m}(t) / \mathrm{d} t=k\left(T_{a}(t)-T_{m}(t)\right)+\dot{T}_{0}$,

where $T_{m}$ is muscle temperature $\left({ }^{\circ} \mathrm{C}\right), T_{a}$ is ambient water temperature $\left({ }^{\circ} \mathrm{C}\right), k$ is whole-body heat transfer coefficient $\left({ }^{\circ} \mathrm{C} \mathrm{min}-1{ }^{\circ} \mathrm{C}^{-1}\right)$, and $\dot{T}_{0}$ is the rate of temperature change due to internal heat production $\left({ }^{\circ} \mathrm{C} \mathrm{min}^{-1}\right)$. To apply this model to our dataset, muscle temperature and ambient water temperature, recorded at $1 \mathrm{~s}$ intervals, were subsampled at 1 min intervals. The differentiation of muscle temperature $\left(\mathrm{d} T_{m}(t) / \mathrm{d} t\right)$ was smoothed using a filter to reduce noise associated with sensor resolutions and plotted against muscle temperature subtracted from ambient temperature $\left(T_{a}(t)-T_{m}(t)\right)$. Given that $\dot{T}_{0}$ is zero for ectothermic blue sharks, the plots were regressed linearly through the origin for the warming process (when $T_{a}(t)-T_{m}(t)$ is positive) and cooling process (when $T_{a}(t)-T_{m}(t)$ is negative) separately. The slopes of the regression lines represented the initial estimates for $k_{\text {warm }}$ and $k_{\text {cool }}$. These values, combined with the time-series records of ambient temperature, allowed us to predict the changes in muscle temperature through time. We produced a set of predictions by changing $k_{\text {warm }}$ and $k_{\text {cool }}$ around the initial estimates and compared them to the actual time-series records of muscle temperature. Using the leastsquares method, we selected a combination of $k_{\text {warm }}$ and $k_{\text {cool }}$ that best fit the muscle temperature records.

\section{Comparative analyses}

Whole-body heat transfer coefficients of fishes, determined experimentally in the laboratory or based on tag data obtained in the field, were compiled from the literature. We only included studies that examined the heat transfer coefficients during the warming process $\left(k_{\text {warm }}\right)$ and cooling process $\left(k_{\text {cool }}\right)$ separately. When body mass was not reported, it was estimated from body length using the published length-weight relationships for the species. When multiple studies were found for a species, we selected the study with the largest sample size. The allometric 
relationships between $k$ values and body mass (in $\mathrm{kg}$ ) were examined by phylogenetically informed statistics. A phylogenetic tree was created for the compiled species with the published relationships among species (Velez-Zuazo and Agnarsson 2011; Betancur-R et al. 2017; Ciezarek et al. 2019) and an arbitrary branch length (Grafen 1989) (Fig. S1). Both predictor (body mass) and response variables ( $k_{\text {warm }}, k_{\text {cool }}$ and the ratio of $k_{\text {warm }}$ to $\left.k_{\text {cool }}\right)$ were $\log _{10}$ transformed, and regression lines were computed under the Ornstein-Uhlenbeck evolutionary process model and nonphylogenetic model (i.e., ordinally least-squares regression) using the Regressionv2 program (Lavin et al. 2008) of the software Matlab (MathWorks). The two models were compared by the Akaike Information Criterion (AIC) to test for the presence of phylogenetic signal (i.e., the tendency for related species to resemble each other).

\section{Results}

We recorded the diving behaviour, ambient water temperature, and muscle temperature of the two female blue sharks tagged (161 and $174 \mathrm{~cm}$ in fork length) for 20-22 h each (Fig. 1). However, muscle temperature data were missing for the last few hours for Shark 2 due to a technical error. Gradual decreases in swim speed (Sundström and Gruber 2002) or tailbeat frequency following the release (Whitney et al. 2016), indicative of a recovery period, were not observed (see swim speed traces in Fig. 1A, B). We thus presume that the effect of capture and tag attachment on shark behaviour was minimal in this study.

Both individuals exhibited similar, repeated vertical movements, with a mean $( \pm \mathrm{SD})$ dive depth and duration of $227 \pm 69 \mathrm{~m}$ and $75 \pm 62 \mathrm{~min}(N=25$ dives $)$, respectively
Fig. 1 Behavioural thermoregulation and foraging during repeated deep dives. The whole 20-22 h time-series data for depth, ambient water temperature, muscle temperature, and swim speed of A Shark 1 and B Shark 2. Red circles on the depth and swim speed traces represent the timings of burst swimming events (i.e., signals of prey capture attempts), including the video-confirmed feeding event on a squid (double circle). Muscle temperature (red line) is shown with its prediction (blue dashed line) based on the ambient water temperature and heat exchange model. Muscle temperature data are missing for the last few hours for Shark 2 due to a technical error. $\mathbf{C}$ Image from animal-borne video camera showing Shark 1 capturing a squid. D Enlarged view of a dive and high-pass filtered lateral acceleration (representing tailbeat activity) of Shark 1 . The shark is negatively buoyant, as indicated by reduced tailbeat activity during decent compared to ascent. Periods of gliding behaviour are denoted by red line on the depth trace
(A) Shark 1
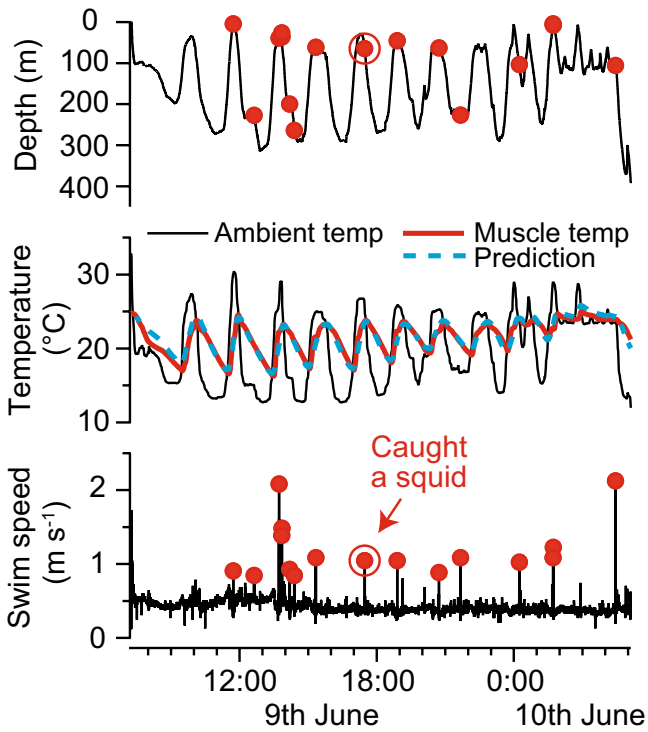

(C)

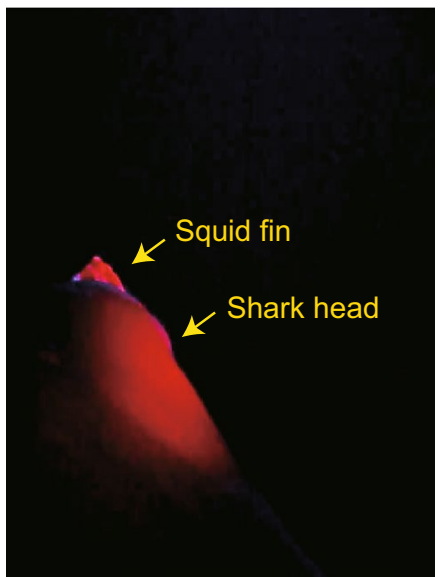

(B) Shark 2
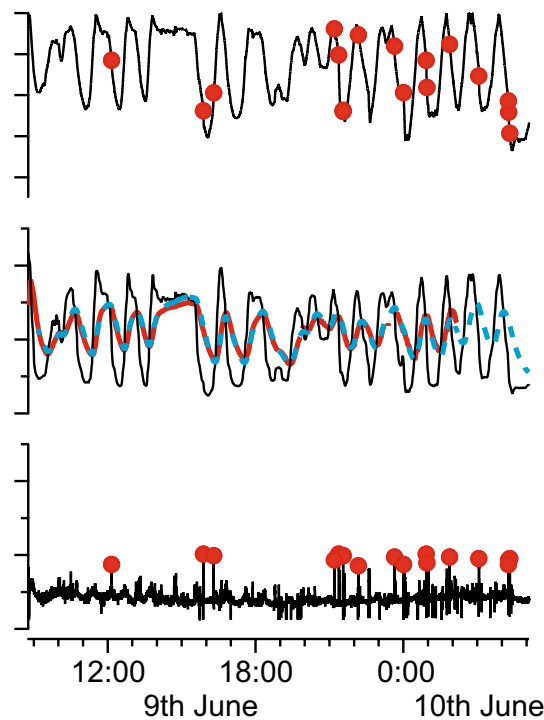

(D)

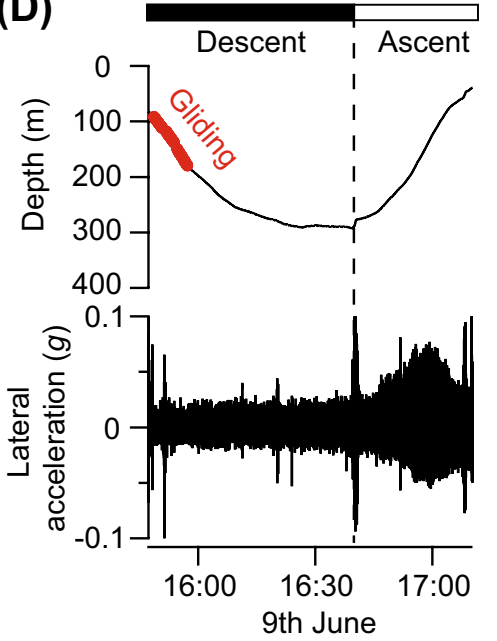


(Table 1, Fig. 1A, B). The maximum depth record was $422 \mathrm{~m}$. Video footage ( $2.5 \mathrm{~h}$ for each individual) showed that Shark 1 captured a squid at 17:28 local time (Fig. 1C); however, other foraging events may have been missed due to the limited view of the mouth from the back-mounted camera. The video-confirmed foraging event corresponded to a burst swimming event (peak speed, $1.0 \mathrm{~m} \mathrm{~s}^{-1}$ ) recorded at $65 \mathrm{~m}$ depth during the descending phase of a dive (Fig. 1A). We thus assumed that burst swimming events recorded in this study represent foraging attempts. Based on a threshold of $0.84 \mathrm{~m} \mathrm{~s}^{-1}$ (i.e., the doubled mean swim speed for both individuals), 17 and 18 burst swimming events were detected for Shark 1 and 2, respectively. The events occurred during the day and night over a wide depth range $(5-293 \mathrm{~m})$ without centring around a particular depth (Figs. 1, 2). Both individual sharks had negative buoyancy, as indicated by decreased amplitudes of lateral acceleration (i.e., tailbeat activities) during descents compared to ascents (Fig. 1D). Gliding behaviour was observed during 10 and $20 \%$ of total descent durations for Shark 1 and 2, respectively.

During the repeated dives, muscle temperature changed more slowly than the ambient water temperature (Fig. 1A, B). Sharks shifted between descents and ascents before their muscle temperature reached the ambient temperature. Consequently, although ambient temperature decreased with depth, muscle temperature was independent of depth and fell in a narrower range $\left(8.4{ }^{\circ} \mathrm{C}\right.$ for both individuals) than ambient temperature $\left(19.7{ }^{\circ} \mathrm{C}\right.$ for Shark 1 and $17.3{ }^{\circ} \mathrm{C}$ for Shark 2) (Table 1, Fig. 2). As expected from the heat exchange model, the rate of changes in muscle temperature was correlated with the difference between ambient water temperature and muscle temperature (Fig. 3). The slopes of the regression lines through the origin provided the initial estimates of heat transfer coefficient (in ${ }^{\circ} \mathrm{C} \min ^{-1}{ }^{\circ} \mathrm{C}^{-1}$ ) during the warming $\left(k_{\text {warm }}\right.$; Shark 1, 0.045; Shark 2, 0.040) and cooling process $\left(k_{\text {cool }}\right.$; Shark 1, 0.014; Shark 2, 0.029). However, variations of the rate of change in muscle temperature for a given temperature difference, especially in Shark 1 (Fig. 3), indicate that these estimates are not necessarily the best for predicting changes in muscle temperature through time from the ambient temperature record. By changing $k_{\text {warm }}$ and $k_{\text {cool }}$ around the initial estimates and fitting the simulated muscle temperature traces to the actual muscle temperature record, we obtained the best estimates for $k_{\text {warm }}$ (Shark 1, 0.044; Shark 2, 0.042) and $k_{\text {cool }}$ (Shark 1, 0.016; Shark 2, 0.030) (Fig. 1A, B). For comparison, both $k_{\text {warm }}$ and $k_{\text {cool }}$ of the dead blue shark (estimated body mass, $60 \mathrm{~kg}$ ) were estimated to be 0.006 . When the size difference was controlled for using the allometric exponents (Fig. 4A), a $29.5-\mathrm{kg}$ (i.e., the mean mass of the two live sharks tagged) dead shark would have $k_{\text {warm }}$ and $k_{\text {cool }}$ of $0.008-0.009$.

$k_{\text {warm }}$ and $k_{\text {cool }}$ were compiled for 23 fish species, including teleosts and elasmobranchs, ranging in body mass from $32 \mathrm{~g}$ to $1300 \mathrm{~kg}$ (Table S1). The phylogenetic
Table 1 Descriptive information and data summary for the blue sharks tagged

\begin{tabular}{|c|c|c|c|c|c|c|c|c|c|}
\hline \multirow[t]{2}{*}{ Shark no } & \multirow{2}{*}{$\begin{array}{l}\text { Fork } \\
\text { length } \\
(\mathrm{cm})\end{array}$} & \multirow{2}{*}{$\begin{array}{l}\text { Estimated } \\
\text { body mass } \\
(\mathrm{kg})\end{array}$} & \multirow[t]{2}{*}{$\begin{array}{l}\text { Recording } \\
\text { duration (h) }\end{array}$} & \multicolumn{2}{|c|}{ Depth $(m)^{\mathrm{a}}$} & \multicolumn{2}{|c|}{$\begin{array}{l}\text { Ambient tempera- } \\
\text { ture }\left({ }^{\circ} \mathrm{C}\right)^{\mathrm{a}}\end{array}$} & \multicolumn{2}{|c|}{$\begin{array}{l}\text { Muscle tempera- } \\
\text { ture }\left({ }^{\circ} \mathrm{C}\right)^{\mathrm{a}}\end{array}$} \\
\hline & & & & Mean & Range & Mean & Range & Mean & Range \\
\hline 1 & 161 & 25.9 & 21.9 & 157 & $1-422$ & 19.7 & $10.7-30.4$ & 21.5 & $16.2-24.6$ \\
\hline 2 & 174 & 33.0 & 20.3 & 130 & $0-335$ & 20.4 & $12.4-29.7$ & 21.1 & $16.6-25.0$ \\
\hline
\end{tabular}

${ }^{\mathrm{a}}$ The initial descent following release from a boat was excluded

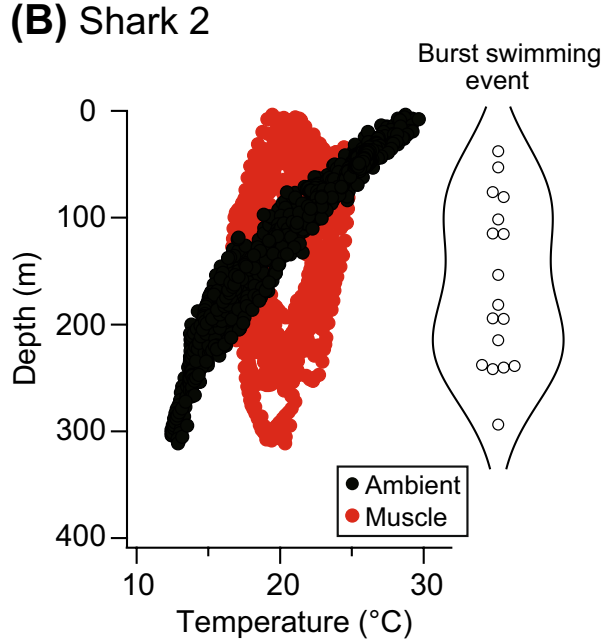

Fig. 2 Ambient water temperature, muscle temperature, and the occurrence of burst swimming events in relation to depth. For both individuals, ambient water temperature (filled circles) decreased with depth, whereas muscle temperature (red circles) was independent of depth. Burst swimming events, a signal of prey capture attempts (open circles shown with estimated probability densities), occurred over a wide depth range

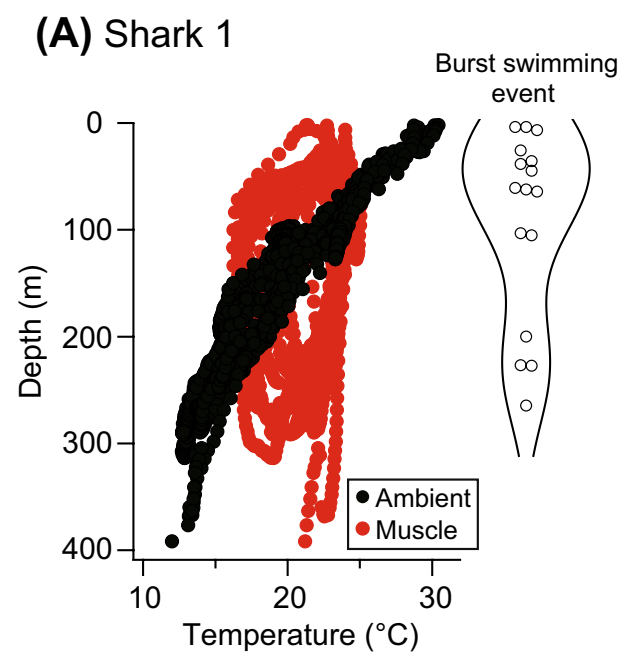


Fig. 3 Applying heat exchange model to tag data. For both individuals, the rate of changes in muscle temperature is plotted against muscle temperature subtracted from ambient water temperature. Positive and negative values on the $x$-axis represent the warming and cooling process, respectively. The slopes of regressions lines through the origin (thick lines) represent the initial estimates for whole-body heat transfer coefficients
(A) Shark 1

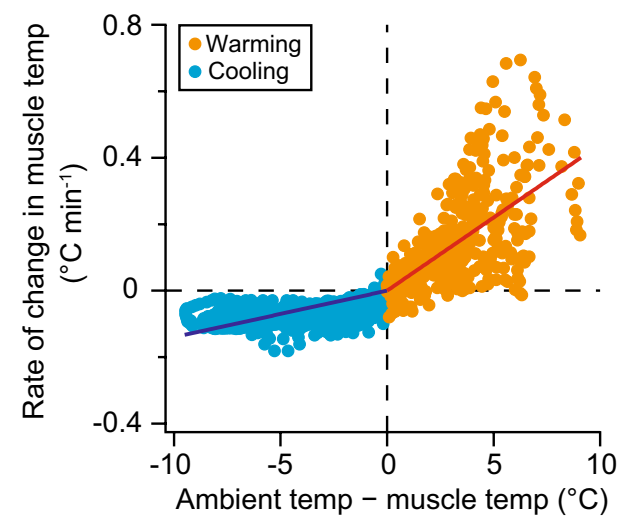

(B) Shark 2

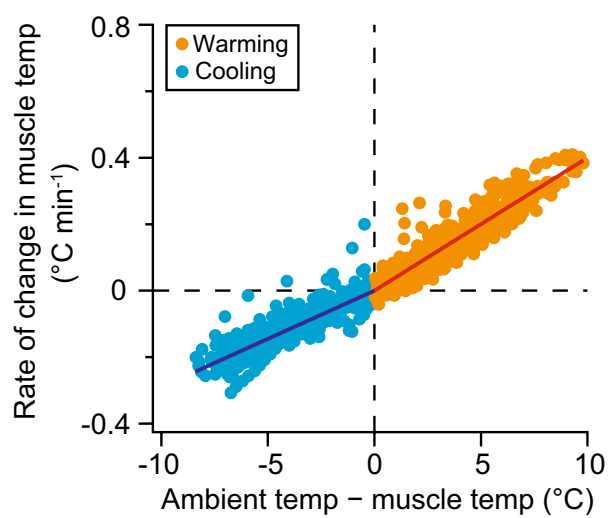

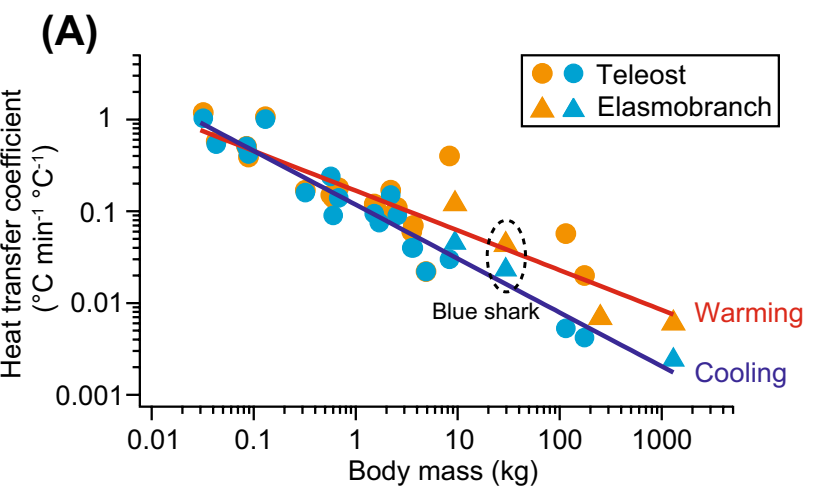

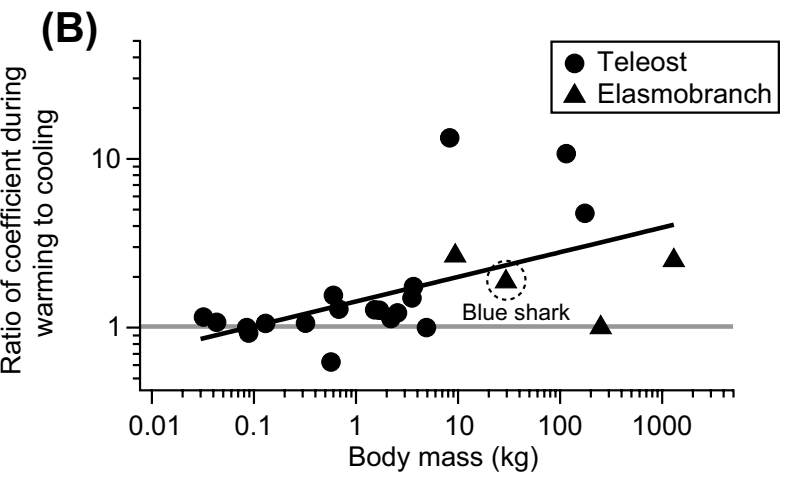

Fig. 4 Allometry of whole-body heat transfer coefficients in fishes. A Heat transfer coefficients plotted against body mass for the warming process (orange symbols) and cooling process (light blue symbols). Non-phylogenetic regression lines are also shown. B The ratio of heat transfer coefficient during the warming process to that during the cooling process plotted against body mass, shown with non-phylogenetic regression line. Grey horizontal bar represents unity (i.e., the ratio is 1). In both $\mathbf{A}$ and $\mathbf{B}$, data for blue sharks are not exceptional. See Table 2 for the equations of regression lines and Table S1 for the compiled data and references

and non-phylogenetic models produced nearly the same allometric equations, with the latter providing a better fit based on AIC, for $k_{\text {warm }}, k_{\text {cool }}$, and the ratio of $k_{\text {warm }}$ to $k_{\text {cool }}$ (Table 2). $k_{\text {warm }}$ decreased with body mass more slowly (exponent -0.44$)$ than $k_{\text {cool }}$ (exponent -0.58$)$ (Fig. 4A). The ratio of $k_{\text {warm }}$ to $k_{\text {cool }}$ increased with body mass (exponent 0.15 ), despite large variations for a given body mass (Fig. 4B). For example, ratios of $>1.3$ were rare ( 1 of 13 species) in the lower body mass range $(<3 \mathrm{~kg})$ but common $(8$ of 10 species) in the upper body mass range ( $>3 \mathrm{~kg}$ ). Neither $k_{\text {warm }}, k_{\text {cool }}$, nor the ratio of $k_{\text {warm }}$ to $k_{\text {cool }}$ of blue sharks were exceptional for their body mass.

\section{Discussion}

\section{Behavioural thermoregulation linked to foraging}

Despite the small sample size, we showed how blue sharks, an ectothermic species with expanded thermal niches, thermoregulate behaviourally. Both individual sharks we tagged moved between the warm surface layer and deep cold water, with the ambient water temperature spanning the range of $\sim 20^{\circ} \mathrm{C}$. Yet, muscle temperature spanned the range of only $8^{\circ} \mathrm{C}$, as reported before (Carey and Scharold 1990). Notably, although ambient temperature decreased with depth, shark muscle temperature was independent of depth when data for the descending and ascending phase of dives were pooled (Fig. 2). This pattern emerged because shark muscle temperature changed slowly due to a large thermal inertia, and because sharks always started descending and ascending before muscle temperature reached the ambient temperature. A similar pattern was reported for bigeye tunas (Malte et al. 2007), a regionally endothermic species with enhanced physiological thermoregulation capabilities (Holland et al. 1992).

Narrower ranges of body temperature than ambient temperature associated with repeated dives have been reported for other pelagic fishes, including bigeye tunas (Malte et al. 2007), ocean sunfish (Nakamura et al. 2015), dolphin fish Coryphaena hippurus (Furukawa et al. 2015), swordfish Xiphias gladius (Stoehr et al. 2018), and whale sharks 
Table 2 Summary for the allometry of heat transfer coefficients in fishes

\begin{tabular}{lllll}
\hline Response variable & Predictor variable & Model & Allometric equation & AIC \\
\hline$k_{\text {warm }}$ & body mass & Non-phylogenetic & $Y=0.169 \times X^{-0.44}$ & $12.3^{\mathrm{a}}$ \\
& & Phylogenetic & $Y=0.167 \times X^{-0.43}$ & 14.3 \\
$k_{\text {cool }}$ & body mass & Non-phylogenetic & $Y=0.118 \times X^{-0.58}$ & $-8.9^{\mathrm{a}}$ \\
& & Phylogenetic & $Y=0.118 \times X^{-0.59}$ & -6.9 \\
$k_{\text {warm }} k_{\text {cool }}$ & \multirow{2}{*}{ body mass } & Non-phylogenetic & $Y=1.43 \times X^{0.15}$ & $10.7^{\mathrm{a}}$ \\
& & Phylogenetic & $Y=1.43 \times X^{0.15}$ & 12.7 \\
\hline
\end{tabular}

${ }^{a}$ Best model by criterion of lowest AIC
Rhincodon typus (Nakamura et al. 2020). However, blue sharks are unique in that their muscle temperature range was in the middle of the ambient temperature range. In other species, body temperature ranges lie in the upper end of ambient temperature ranges. Blue sharks appear to avoid both excessive decreases and increases in muscle temperature by alternating descents and ascents, whereas other species studied to date avoid overcooling by rewarming at shallow depths after the excursions to deep cold waters. Note, however, that heart remains at the ambient water temperature in nearly all fishes (including both ectothermic and regionally endothermic species), except for opah Lampris guttatus (Wegner et al. 2015). Temperature dependence of cardiac functions, rather than muscle functions, may ultimately limit the diving behaviour of large pelagic fishes.

Given the global distribution of blue sharks in tropical and temperate waters, the pattern we observed is likely specific to the water column structure. In this study and Carey's study (Carey and Scharold 1990), the water was well stratified, and sea surface temperature was high $\left(26-30^{\circ} \mathrm{C}\right)$ (Fig. 2). Long-term diving records showed that, in blue sharks (Campana et al. 2011; Braun et al. 2019; Vedor et al. 2021) and other ectothermic pelagic sharks (Andrzejaczek et al. 2018), repeated deep-diving behaviour (as we observed in this study) is associated with stratified water columns and high sea surface temperatures. Therefore, blue sharks may thermoregulate and forage in different manners in mixed water columns and higher latitudes (or cooler seasons) with lower sea surface temperatures. Carey and Gibson recorded blue shark body temperature and diving behaviour when the sea surface temperature was only $18-19{ }^{\circ} \mathrm{C}$ (Carey and Gibson 1987). Their data (Fig. 4 of the study) suggest that, like ocean sunfish (Nakamura et al. 2015), blue sharks stay at the surface for prolonged periods following deep dives until their bodies fully rewarm.

The behavioural thermoregulation of blue sharks appears to be linked to foraging behaviour. Our video footage showed that a shark caught a squid, among the main diets of this species (Markaida and Sosa-Nishizaki 2010). Our video recording duration was limited to $2.5 \mathrm{~h}$ for each animal. Nevertheless, the video-confirmed feeding event corresponded to a burst swimming event, allowing us to detect similar burst swimming events as signals of prey capture attempts from the entire tag data. Some of the burst swimming events may represent evasions from predators (e.g., shortfin mako sharks Isurus oxyrinchus); however, encounter rates with predators are likely low for the size of blue sharks tagged in this study. The burst swimming events occurred over a wide depth range $(5-293 \mathrm{~m})$ (Figs. 1 and 2), suggesting that blue sharks maximise prey encounter rates by moving vertically. This pattern contrasts with ocean sunfish, which forage during the bottom phase of deep dives, as shown by a similar biologging package to that used in this study (Nakamura et al. 2015).

Overall, our results suggest that behavioural thermoregulation linked to foraging is a major function of repeated deep dives in blue sharks, although more tagging experiments are needed to draw firm conclusions. Some large sharks appear to save locomotion costs by gliding with negative buoyancy during descent (Gleiss et al. 2011a, b; Watanabe et al. 2019). Animals incur less hydrodynamic drag during gliding than active swimming; therefore, in theory, negatively buoyant animals can save locomotion cost by alternating passive gliding in descents and active swimming in ascents compared with continuous horizontal swimming (Weihs 1973). However, as for tiger sharks Galeocerdo cuvier (Nakamura et al. 2011) and Greenland sharks Somniosus microcephalus (Watanabe et al. 2012), the blue sharks tagged in this study glided only for a minor proportion $(10-20 \%)$ of their descent durations, indicating that locomotion cost saving is not the main explanation for deep dives. In some pelagic fishes, deep dives may be associated with navigation because geomagnetic and bathymetric cues can be accessed at great depths (Klimley 1993). This possibility cannot be ruled out for blue sharks. Nevertheless, the remarkably regular deep-diving behaviour of this species, reported off Taiwan (this study) and other areas (Carey and Scharold 1990; Stevens et al. 2010; Campana et al. 2011), can be parsimoniously explained by their motivation for maintaining body temperature within a narrow range while foraging in the stratified water columns. 


\section{Control of heat exchange rates}

Despite some variations between the two individuals, the heat exchange model that considers the warming and cooling process separately fit our data well (Fig. 1A, B and 3). It showed that $k_{\text {warm }}$ is approximately twice higher than $k_{\text {cool }}$. A previous study that reanalysed Carey and Scharold (1990) data on a single blue shark found a four-fold higher $k_{\text {warm }}$ than $k_{\text {cool }}$ (Bernal et al. 2001). These results indicate that blue sharks change heat exchange rates depending on the phase of dives, as reported for bigeye tunas (Holland et al. 1992) and ocean sunfish (Nakamura et al. 2015). In the case of bigeye tunas with developed counter-current heat exchangers, an important mechanism is to pass the blood through the heat exchangers or bypass them depending on dive phases (Boye et al. 2009). However, this option is not available for ectothermic blue sharks, which do not possess counter-current heat exchangers. We postulate that their increased heat exchange rates during the warming process (or ascending phase) are associated with the increased tailbeat activities (as we observed) and associated increases in gas and heat exchange through the gill in this negatively buoyant shark. Additional information (e.g., heart rate) are needed to better understand how blue sharks change their heat exchange rates during diving. Not surprisingly, $k_{\text {warm }}$ equalled $k_{\text {cool }}$ in the dead blue shark we examined. Moreover, $k_{\text {warm }}$ and $k_{\text {cool }}$ of the dead shark were much lower than those of live sharks even after controlling for the size difference. This result confirms that heat exchange between fish bodies and the ambient water are greatly reduced in the absence of convective heat transfer due to blood flow, as shown previously (Spigarelli et al. 1977; Weller et al. 1984; Carey and Gibson 1987; Nakamura et al. 2015).

Our comparative analyses showed that both $k_{\text {warm }}$ and $k_{\text {cool }}$ decrease with body mass in fishes (Fig. 4A). Nonphylogenetic models provided a better fit than phylogenetic models, indicating that little phylogenetic signals are present in mass-adjusted heat transfer coefficients. Our result of negative allometry agrees with previous intraand inter-specific comparisons of $k$ value in fishes; however, previous studies had much narrower body size range than the present study (Stevens and Fry 1970, 1974; Fechhelm and Neill 1982; Weller et al. 1984; Kubo et al. 2008; Coffey et al. 2020) or analysed only $k_{\text {cool }}$ (Nakamura et al. 2020). Heat is transferred via conduction across body surface and via convection through the gill (Carey and Gibson 1987; Boye et al. 2009). Therefore, negative allometry is likely a result of (i) decreasing surface-area-to-volume ratio with increasing body mass (leading to decreasing heat conduction per a unit body mass) and (ii) decreasing mass-specific metabolic rates with increasing body mass (leading to decreasing heat convection per a unit body mass). Yet, the exponents we observed ( -0.44 for $k_{\text {warm }}$,
-0.58 for $k_{\text {cool }}$ ) were lower than those predicted from the allometry of surface-area-to-volume ratio $\left(\mathrm{mass}^{-1 / 3}\right)$ and mass-specific metabolic rates (mass ${ }^{-0.2--0.1}$; (White et al. 2007)). An explanation for this discrepancy is that body temperature tends to be measured at a point progressively further from the body surface in larger fishes (Stevens and Fry 1974; Nakamura et al. 2020). In other words, temperature gradients between the body surface and the point where body temperature is measured tend to be smaller in larger fishes for a given temperature difference.

$k_{\text {warm }}$ decreased with body mass more slowly than $k_{\text {cool }}$, meaning that $k_{\text {warm }}$ becomes larger relative to $k_{\text {cool }}$ as body size increases. As another way to assess this pattern, the ratio of $k_{\text {warm }}$ to $k_{\text {cool }}$ increased with body mass, with the ratio of $>1.3$ being common only in large fishes ( $>3 \mathrm{~kg}$ in body mass) (Fig. 4B). Our results indicate that the ability to change heat exchange rates is more developed in larger fishes, partly due to their lower surface-area-to-volume ratios. In very small fishes, body temperature equilibrates with the ambient temperature quickly, leaving little room for the control of heat exchange rates. Moreover, the presence of counter-current heat exchangers in some species, including bigeye tunas (Malte et al. 2007) and swordfish (Stoehr et al. 2018), is apparently associated with their high (>10) $k_{\text {warm }} / k_{\text {cool }}$ ratio through the mechanism described earlier. Neither $k_{\text {warm }}, k_{\text {cool }}$, nor the ratio of $k_{\text {warm }}$ to $k_{\text {cool }}$ of blue sharks were exceptional among fishes for their body mass (Fig. 4). Our results imply that blue sharks do not have enhanced ability to control heat exchange rates.

In conclusion, despite the small sample size, we showed that blue sharks behaviourally thermoregulate and forage during repeated deep dives. They maintain their body temperature within a narrow range by starting ascents before their bodies exceedingly cool down and starting descents before their bodies exceedingly warm up. During such repeated dives, they search for prey (e.g., squids) distributed widely in the water column. Their ability to control heat exchange rates, as assessed by whole-body heat transfer coefficients, is normal for their body size. Additional information (e.g., heart rate) are needed to elucidate how blue sharks and other ectothermic fishes change heat exchange rate during diving. Our study suggests that behavioural thermoregulation linked to foraging, rather than enhanced abilities to control heat exchange rates, is key to the vertically and geographically expanded thermal niches of blue sharks.

Supplementary Information The online version contains supplementary material available at https://doi.org/10.1007/s00227-021-03971-3.

Acknowledgements We thank the captain M-C. Chen and the crew of his boat for their help in tagging sharks, the captain J-A. Jenq for his help in recovering tags, S-J. Lin, Q-X. Chang, and other staff at Eastern Marine Biology Research Center for their help in the field and lab experiments, and J. M. Semmens for editing English. 
Author contributions YYW, IN, and W-CC designed research; YYW, IN, and W-CC performed research; YYW analysed data; and YYW wrote the paper with inputs from IN and W-CC.

Funding This work was funded by Grants-in-Aids for Scientific Research from the Japan Society for the Promotion of Science (JSPS) (16H04973 and 18KK0293 to Y.Y.W) and Fisheries Research Institute, Council of Agriculture, Taiwan (109AS-9.1.2-A-A1 to W-C.C).

Data availability Data used in the comparative analyses are available in Table S1 of Supplementary information.

\section{Declarations}

Conflicts of interest The authors have no conflicts of interest to declare.

Ethics approval The treatment of animals was reviewed and approved by Fisheries Research Institute, Taiwan.

\section{References}

Andrzejaczek S, Gleiss AC, Jordan LK, Pattiaratchi CB, Howey LA, Brooks EJ, Meekan MG (2018) Temperature and the vertical movements of oceanic whitetip sharks, Carcharhinus Longimanus. Sci Rep 8:8351. https://doi.org/10.1038/s41598-018-26485-3

Andrzejaczek S, Gleiss AC, Pattiaratchi CB, Meekan MG (2019) Patterns and drivers of vertical movements of the large fishes of the epipelagic. Rev Fish Biol Fish 29:335-354. https://doi.org/10. 1007/s11160-019-09555-1

Bernal D, Sepulveda C, Graham JB (2001) Water-tunnel studies of heat balance in swimming mako sharks. J Exp Biol 204:4043-4054. https://doi.org/10.1242/jeb.204.23.4043

Betancur-R R, Wiley EO, Arratia G, Acero A, Bailly N, Miya M, Lecointre G, Orti G (2017) Phylogenetic classification of bony fishes. BMC Evol Biol 17:1-40. https://doi.org/10.1186/ s12862-017-0958-3

Block BA, Finnerty JR, Stewart AFR, Kidd J (1993) Evolution of endothermy in fish: mapping physiological traits on a molecular phylogeny. Science 260:210-214. https://doi.org/10.1126/scien ce.8469974

Boye J, Musyl M, Brill R, Malte H (2009) Transectional heat transfer in thermoregulating bigeye tuna (Thunnus obesus) - a 2D heat flux model. J Exp Biol 212:3708-3718. https://doi.org/10.1242/ jeb.031427

Braun CD, Gaube P, Sinclair-Taylor TH, Skomal GB, Thorrold SR (2019) Mesoscale eddies release pelagic sharks from thermal constraints to foraging in the ocean twilight zone. Proc Natl Acad Sci USA 116:17187-17192. https://doi.org/10.1073/pnas.1903067116

Campana SE, Dorey A, Fowler M, Joyce W, Wang Z, Wright D, Yashayaev I (2011) Migration pathways, behavioural thermoregulation and overwintering grounds of blue sharks in the Northwest Atlantic. PLoS ONE 6:e16854. https://doi.org/10.1371/journal. pone. 0016854

Carey FG, Gibson QH (1987) Blood flow in the muscle of free-swimming fish. Physiol Zool 60:138-148

Carey FG, Scharold JV (1990) Movements of blue sharks (Prionace glauca) in depth and course. Mar Biol 106:329-342. https://doi. org/10.1007/bf01344309

Ciezarek AG, Osborne OG, Shipley ON, Brooks EJ, Tracey SR, McAllister JD, Gardner LD, Sternberg MJ, Block B, Savolainen V (2019) Phylotranscriptomic insights into the diversification of endothermic Thunnus tunas. Mol Biol Evol 36:84-96. https://doi. org $/ 10.1093 / \mathrm{molbev} / \mathrm{msy} 198$

Coffey DM, Royer MA, Meyer CG, Holland KN (2020) Diel patterns in swimming behavior of a vertically migrating deepwater shark, the bluntnose sixgill (Hexanchus griseus). PLoS ONE 15:e0228253. https://doi.org/10.1371/journal.pone.0228253

Fechhelm RG, Neill WH (1982) Predicting body-core temperature in fish subjected to fluctuating ambient temperature. Physiol Zool 55:229-239

Furukawa S, Chiang W, Watanabe S, Hung H, Lin H, Yeh H, Wang S, Tone K, Kawabe R (2015) The first record of peritoneal cavity temperature recording in free-swimming dolphinfish Coryphaena hippurus by using archival tags, on the east coast of Taiwan. J Aquacult Mar Biol 2:00032. https://doi.org/10.15406/ jamb.2015.02.00032

Giske J, Aksnes DL, Baliño BM, Kaartvedt S, Lie U, Nordeide JT, Salvanes AGV, Wakili SM, Aadnesen A (1990) Vertical distribution and trophic interactions of zooplankton and fish in Masfjorden, Norway. Sarsia 75:65-81. https://doi.org/10.1080/ 00364827.1990 .10413442

Gleiss AC, Jorgensen SJ, Liebsch N, Sala JE, Norman B, Hays GC, Quintana F, Grundy E, Campagna C, Trites AW (2011a) Convergent evolution in locomotory patterns of flying and swimming animals. Nat Commun 2:352. https://doi.org/10.1038/ ncomms 1350

Gleiss AC, Norman B, Wilson RP (2011b) Moved by that sinking feeling: variable diving geometry underlies movement strategies in whale sharks. Funct Ecol 25:595-607. https://doi.org/ 10.1111/j.1365-2435.2010.01801.x

Grafen A (1989) The phylogenetic regression. Phil Trans Roy Soc B 326:119-157. https://doi.org/10.1098/rstb.1989.0106

Harding L, Jackson A, Barnett A, Donohue I, Halsey L, Huveneers C, Meyer C, Papastamatiou Y, Semmens JM, Spencer E (2021) Endothermy makes fishes faster but does not expand their thermal niche. Funct Ecol 35:1951-1959. https://doi.org/10.1111/ 1365-2435.13869

Hays GC (2003) A review of the adaptive significance and ecosystem consequences of zooplankton diel vertical migrations. Hydrobiologia 503:163-170. https://doi.org/10.1007/978-94017-2276-6_18

Holland KN, Brill RW, Chang RK, Sibert JR, Fournier DA (1992) Physiological and behavioural thermoregulation in bigeye tuna (Thunnus obesus). Nature 358:410-412. https://doi.org/10.1038/ $358410 \mathrm{a} 0$

Kawatsu S, Sato K, Watanabe Y, Hyodo S, Breves JP, Fox BK, Grau EG, Miyazaki N (2010) A new method to calibrate attachment angles of data loggers in swimming sharks. EURASIP J Adv Signal Process 2010:732586. https://doi.org/10.1155/2010/732586

Klimley A (1993) Highly directional swimming by scalloped hammerhead sharks, Sphyrna lewini, and subsurface irradiance, temperature, bathymetry, and geomagnetic field. Mar Biol 117:1-22. https://doi.org/10.1007/BF00346421

Kohler NE, Casey JG, Turner PA (1995) Length-weight relationships for 13 species of sharks from the Western North Atlantic. Fish Bull 93:412-418

Kubo T, Sakamoto W, Murata O, Kumai H (2008) Whole-body heat transfer coefficient and body temperature change of juvenile Pacific bluefin tuna Thunnus orientalis according to growth. Fish Sci 74:995-1004. https://doi.org/10.1111/j.1444-2906.2008. 01617.x

Lavin SR, Karasov WH, Ives AR, Middleton KM, Garland T Jr (2008) Morphometrics of the avian small intestine compared with that of nonflying mammals: a phylogenetic approach. Physiol Biochem Zool 81:526-550. https://doi.org/10.1086/590395 
Longhurst AR (1967) Vertical distribution of zooplankton in relation to the eastern Pacific oxygen minimum. Deep-Sea Res 14:51-63. https://doi.org/10.1016/0011-7471(67)90028-9

Malte H, Larsen C, Musyl M, Brill R (2007) Differential heating and cooling rates in bigeye tuna (Thunnus obesus Lowe): a model of non-steady state heat exchange. J Exp Biol 210:2618-2626. https://doi.org/10.1242/jeb.003855

Markaida U, Sosa-Nishizaki O (2010) Food and feeding habits of the blue shark Prionace glauca caught off Ensenada, Baja California, Mexico, with a review on its feeding. J Mar Biol Assoc UK 90:977-994. https://doi.org/10.1017/S0025315409991597

Nakamura I, Watanabe YY, Papastamatiou YP, Sato K, Meyer CG (2011) Yo-yo vertical movements suggest a foraging strategy for tiger sharks Galeocerdo cuvier. Mar Ecol Prog Ser 424:237-246. https://doi.org/10.3354/meps08980

Nakamura I, Goto Y, Sato K (2015) Ocean sunfish rewarm at the surface after deep excursions to forage for siphonophores. J Anim Ecol 84:590-603. https://doi.org/10.1111/1365-2656.12346

Nakamura I, Matsumoto R, Sato K (2020) Body temperature stability in the whale shark, the world's largest fish. J Exp Biol 223(11):jeb210286. https://doi.org/10.1242/jeb.210286

Queiroz N, Humphries NE, Noble LR, Santos AM, Sims DW (2012) Spatial dynamics and expanded vertical niche of blue sharks in oceanographic fronts reveal habitat targets for conservation. PLoS One 7:e32374. https://doi.org/10.1371/journal.pone.00323 74

Queiroz N, Vila-Pouca C, Couto A, Southall EJ, Mucientes G, Humphries NE, Sims DW (2017) Convergent foraging tactics of marine predators with different feeding strategies across heterogeneous ocean environments. Front Mar Sci 4:239. https://doi.org/10.3389/ fmars.2017.00239

Spigarelli S, Thommes M, Beitinger T (1977) The influence of body weight on heating and cooling of selected Lake Michigan fishes. Comp Biochem Physiol A Mol Integr Physiol 56:51-57. https:// doi.org/10.1016/0300-9629(77)90441-8

Stevens ED, Fry F (1970) The rate of thermal exchange in a teleost, Tilapia mossambica. Can J Zool 48:221-226. https://doi.org/10. 1139/z70-036

Stevens ED, Fry FEJ (1974) Heat transfer and body temperatures in non-thermoregulatory teleosts. Can J Zool 52:1137-1143. https:// doi.org/10.1139/z74-152

Stevens JD, Bradford RW, West GJ (2010) Satellite tagging of blue sharks (Prionace glauca) and other pelagic sharks off eastern Australia: depth behaviour, temperature experience and movements. Mar Biol 157:575-591. https://doi.org/10.1007/ s00227-009-1343-6

Stoehr A, St. Martin J, Aalbers S, Sepulveda C, Bernal D (2018) Freeswimming swordfish, Xiphias gladius, alter the rate of whole body heat transfer: morphological and physiological specializations for thermoregulation. ICES J Mar Sci 75:858-870. https://doi.org/10. 1093/icesjms/fsx163

Sundström L, Gruber S (2002) Effects of capture and transmitter attachments on the swimming speed of large juvenile lemon sharks in the wild. J Fish Biol 61:834-838. https://doi.org/10. 1111/j.1095-8649.2002.tb00914.x

Tanaka H, Takagi Y, Naito Y (2001) Swimming speeds and buoyancy compensation of migrating adult chum salmon Oncorhynchus keta revealed by speed/depth/acceleration data logger. J Exp Biol 204:3895-3904. https://doi.org/10.1242/jeb.204.22.3895

Vedor M, Mucientes G, Hernández-Chan S, Rosa R, Humphries N, Sims DW, Queiroz N (2021) Oceanic diel vertical movement patterns of blue sharks vary with water temperature and productivity to change vulnerability to fishing. Front Mar Sci 8:688076. https:// doi.org/10.3389/fmars.2021.688076

Velez-Zuazo X, Agnarsson I (2011) Shark tales: a molecular specieslevel phylogeny of sharks (Selachimorpha, Chondrichthyes). Mol Phylogen Evol 58:207-217. https://doi.org/10.1016/j.ympev.2010. 11.018

Watanabe YY, Takahashi A (2013) Linking animal-borne video to accelerometers reveals prey capture variability. Proc Natl Acad Sci USA 110:2199-2204. https://doi.org/10.1073/pnas.1216244110

Watanabe Y, Baranov EA, Sato K, Naito Y, Miyazaki N (2004) Foraging tactics of Baikal seals differ between day and night. Mar Ecol Prog Ser 279:283-289. https://doi.org/10.3354/meps279283

Watanabe Y, Wei Q, Yang D, Chen X, Du H, Yang J, Sato K, Naito Y, Miyazaki N (2008) Swimming behavior in relation to buoyancy in an open swimbladder fish, the Chinese sturgeon. J Zool 275:381-390. https://doi.org/10.1111/j.1469-7998.2008.00451.x

Watanabe YY, Lydersen C, Fisk AT, Kovacs KM (2012) The slowest fish: Swim speed and tail-beat frequency of Greenland sharks. J Exp Mar Biol Ecol 426:5-11. https://doi.org/10.1016/j.jembe. 2012.04.021

Watanabe YY, Payne NL, Semmens JM, Fox A, Huveneers C (2019) Swimming strategies and energetics of endothermic white sharks during foraging. J Exp Biol 222:jeb185603. https://doi.org/10. $1242 /$ jeb. 185603

Wegner NC, Snodgrass OE, Dewar H, Hyde JR (2015) Whole-body endothermy in a mesopelagic fish, the opah, Lampris guttatus. Science 348:786-789. https://doi.org/10.1126/science.aaa8902

Weihs D (1973) Mechanically efficient swimming techniques for fish with negative buoyancy. J Mar Res 31:194-209

Weller DE, Anderson DJ, DeAngelis DL, Coutant CC (1984) Rates of heat exchange in largemouth bass: experiment and model. Physiol Zool 57:413-427

Weng KC, Castilho PC, Morrissette JM, Landeira-Fernandez AM, Holts DB, Schallert RJ, Goldman KJ, Block BA (2005) Satellite tagging and cardiac physiology reveal niche expansion in salmon sharks. Science 310:104-106. https://doi.org/10.1126/science. 1114616

White CR, Cassey P, Blackburn TM (2007) Allometric exponents do not support a universal metabolic allometry. Ecology 88:315-323. https://doi.org/10.1890/05-1883

Whitney NM, White CF, Gleiss AC, Schwieterman GD, Anderson P, Hueter RE, Skomal GB (2016) A novel method for determining post-release mortality, behavior, and recovery period using acceleration data loggers. Fish Res 183:210-221. https://doi.org/ 10.1016/j.fishres.2016.06.003

Publisher's Note Springer Nature remains neutral with regard to jurisdictional claims in published maps and institutional affiliations. 